\title{
Development of Flow Field and Temperature Distribution during Changing Divergent Angle of the Nozzle When Using Swirl Flow in a Square Continuous Casting Billet Mould
}

\author{
Shavkat KHOLMATOV, ${ }^{1)}$ Shigeo TAKAGI, ${ }^{2)}$ Lage JONSSON, ${ }^{1)}$ Pär JÖNSSON") and Shinichiro YOKOYA ${ }^{1,2)}$ \\ 1) Division of Applied Process Metallurgy, Royal Institute of Technology, Brinellvägen 23, SE-100 44 Stockholm, Sweden. \\ 2) Department of Mechanical Engineering, Nippon Institute of Technology, Miyashiro, Saitama 345-8501 Japan.
}

(Received on May 19, 2006; accepted on September 11, 2006)

\begin{abstract}
Recently, positive effects of swirl flow have been investigated, related to specific billet moulds with particular divergent angles in the immersion nozzles. ${ }^{1-7)}$ Literature review showed that a systematic study of changes in the divergent angle in the immersion nozzle for continuous casting moulds had not been carried out. Therefore, in the present work we aim to investigate the development of flow field and temperature distribution inside the mould and on the meniscus while changing the divergent angle of the immersion nozzle. Swirl flow was used in the nozzle and the liquid entered a 3D square billet mould. Both physical and mathematical modelling was carried out to simulate nine different divergent angles between 0 and $160^{\circ}$. The overall results of the study showed that a change in divergent angle has an effect on the flow pattern as well as the temperature distribution of the liquid steel in the mould.

More specifically it was found that in the case of $100^{\circ}$ divergent angle nozzle billet we can observe a major shift of lower circulation compared to that of the $80^{\circ}$ nozzle billet. Furthermore, a noticeable increase of the temperature near the meniscus, for a square billet, and radial velocity component, for a round billet, was found when using the $100^{\circ}$ divergent angle nozzle compared to the $80^{\circ}$ divergent angle nozzle. Additionally, a uniform velocity and heat distribution was observed within a distance of $200 \mathrm{~mm}$ below the nozzle exit for nozzle outlets with $100^{\circ}$ divergent angles and larger.
\end{abstract}

KEY WORDS: swirl flow; divergent angle of the immersion nozzle; billet continuous casting mould.

\section{Introduction}

In the continuous casting process it is well known that flow pattern in the mould has a key effect on final products. The flow pattern is highly influenced by the way in which the steel is fed into the mould. Mould flux entrapment resulting from the vortexing and shearing action of the oscillating surface waves have become of particular concern. One way of changing the flow in a nozzle is to use a swirl flow created by a swirl blade. Swirl flow phenomena have been extensively studied by Yokoya et $a{ }^{1-7)}$ In the earlier research it was shown that swirl flow helps to control the flow pattern in the mould. In addition, the use of swirl flow enhances heat and mass transfer and helps the superheat in melt to dissipate.

Literature review of several papers by Yokoya et al. ${ }^{1-7)}$ showed that previous research had focused on applying swirl flow to billet continuous casting (CC) moulds considering only specific divergent angle in the immersion nozzle outlet. Yokoya et al. showed that:

- A weak impinging flow was observed near the corner of the mould-wall, which results in the promotion of uniform heat and mass transfer across the plane, particularly at the casting corners. ${ }^{1)}$

- Uniform velocity distribution was obtained within a short distance of the outlet of the nozzle..$^{2-4)}$

- Swirl helps the superheat in the melt dissipate..$^{2-4)}$

- Using swirl flow, a stable bulk flow in the mould was obtained for high throughput cases. ${ }^{5-7)}$

It is reasonable for a swirling velocity in the immersion nozzle to be as weak as possible. If a reasonable divergent angle is considered, only a weak flow is required to prevent separation from the wall of the immersion nozzle, and to control the flow pattern at the outlet of the immersion and in the mould. ${ }^{8)}$

A summary paper written by Thomas ${ }^{9)}$ reviews the development of the mould continuous casting process, discussing past, present and future prospects. Fluid flow development in the mould is extensively discussed, which includes work done in the mould shell solidification models, mould thermal distortion, thermal stress analysis, etc.; in general, all aspects of fluid pattern in the mould are reviewed and summarized. ${ }^{9)}$ This motivated us to study the divergent angle of the immersion nozzle, which has not been a topic of study. Additionally, effects of swirl flow applied in the process are of particular concern, which is the aim of this study. The study consisted of both physical and mathematical modelling.

Object of our study is a square billet CC mould; however, 
the results can be applied to blooms and slab moulds. Initially, a mathematical model with a $90^{\circ}$ divergent angle mould was developed and verified with experimental measurements. Thereafter, studies were continued by introducing billets having divergent angles of 0 to $160^{\circ}$ in the immersion nozzle.

In the first part of the paper the experimental setup and the mathematical model is described. Thereafter, results from physical modelling as well as mathematical modelling are presented. Finally, the influence of the divergent angle in the nozzle on the flow pattern and temperature distribution in the mould is discussed.

\section{Experimental Work}

Physical modelling of the billet mould was carried out using an experimental setup shown in Fig. 1. An immersion nozzle of $18 \mathrm{~mm}$ diameter with a swirl blade mounted in it is part of the experimental setup. The square mould has the dimensions $133 \times 133 \times 1000 \mathrm{~mm}$. The depth of the nozzle tube is $93 \mathrm{~mm}$ and the swirl blade is placed at the upstream end of the nozzle (Fig. 1). Initially, a billet mould with $90^{\circ}$ divergent angle in the immersion nozzle was considered. A detailed picture of the nozzle is shown in Fig. 2. Thereafter, the divergent angle was steadily changed. This divergent angle is defined as the angle between tangential lines at both curved inner walls of the nozzle tube, as shown in Fig. 2. It should be noted that for a billet mould with $0^{\circ}, 20^{\circ}$ and $40^{\circ}$ divergent angles, in the immersion nozzle the diameters of the tube (nozzle) exit are reduced to 18, 30.3, and $39.8 \mathrm{~mm}$, respectively (instead of $56 \mathrm{~mm}$ ). This reduction of the diameter is caused by the geometry of the nozzle, since the length of the tube below swirl blade is predetermined, and the original nozzle exit diameter was $56 \mathrm{~mm}$. However, for all other studied nozzles having a divergent angle greater than $60^{\circ}$ the tube outlet diameter is set to $56 \mathrm{~mm}$, as shown on Fig 2.

Water was used to simulate steel. An overflow tank was used to obtain a constant fluid velocity through the nozzle. The desired swirl flow was obtained by placing a swirl blade at the upstream end of the nozzle tube. Axial $(v)$, radial $(u)$ and tangential velocity $(w)$ profiles were measured using a Laser Doppler Velocimeter (LDV), mounted on a traversing device. The LDV equipment used a two-dimensional $4 \mathrm{~W}$ Ar laser. The water was seeded with 3 micron alumina powder particles to facilitate the measurements. The $\mathrm{X}, \mathrm{Y}$ and $\mathrm{Z}$ direction velocities were measured every $3 \mathrm{~mm}$ in each direction using the LDV. Furthermore, the mean velocity through the tube was measured by an electromagnetic velocimeter and found to be $2 \mathrm{~m} / \mathrm{s}$. The resulting Reynolds number and throughput were 38000 and $1.73 \mathrm{~m} / \mathrm{min}$, respectively. Considering a Froude-number of similarity, for the cases of dimensions $200 \times 200$ and $300 \times 300$, the throughputs are 2.1 and $2.6 \mathrm{~m} / \mathrm{min}$, respectively.

\section{Mathematical Model}

A three-dimensional (3D) mathematical model of the billet CC mould shown in Fig. 1 was developed. The assumptions made, general transport equations and boundary con-

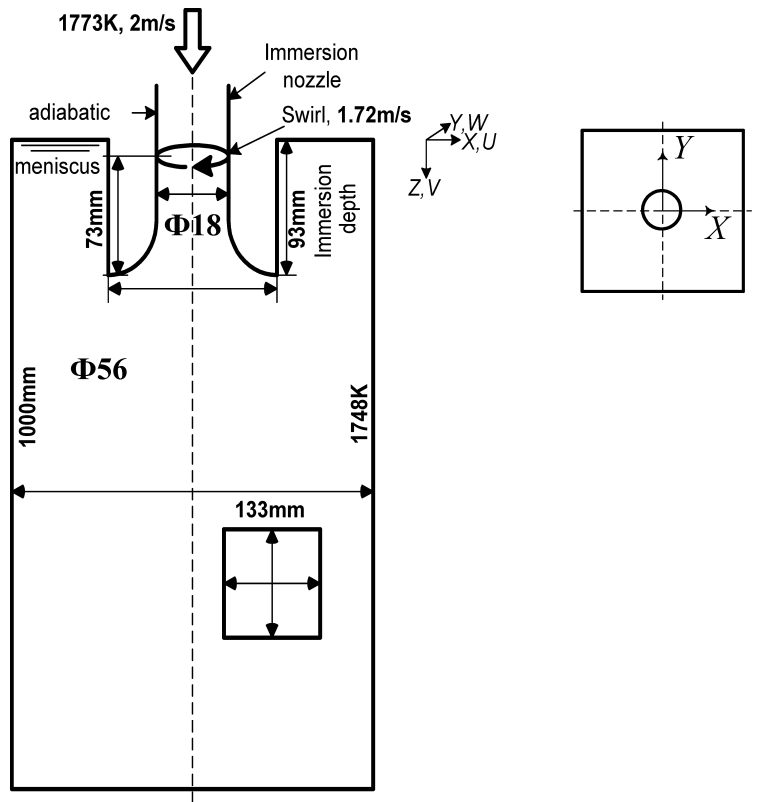

Fig. 1. Schematic of experimental equipment, showing details of experimental equipment, computational mould, boundary conditions, immersion nozzle and the swirl blade.

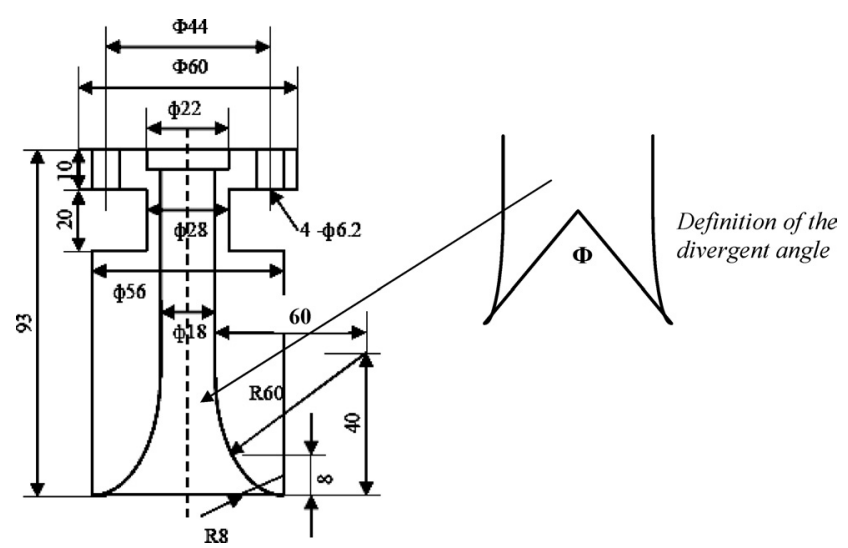

Fig. 2. An overview of water-model, and mould with $\Phi$ divergent angle in the immersion nozzle outlet.

ditions are specified below. The model is an extension of previous work, ${ }^{1-7)}$ where details regarding the transport and turbulence equations can be found.

\subsection{Assumptions}

The following assumptions are made in the statement of the mathematical model of the 3D billet continuous caster mould:

- The calculations are made using the steady-state mode;

- No solidification is considered;

- The free surface is flat.

\subsection{Transport Equations}

According to the above assumptions, the following general transport and turbulence equations need to be solved:

- Conservation of mass;

- Conservation of momentum;

- Energy equation;

- Standard two-equation $k-\varepsilon$ turbulence model: The used swirl number $\mathrm{Sw}$ is defined as $2 w / 3 v$, where $w$ and $v$ are 
the tangential and axial mean velocities across the nozzle tube. In my several studies using a water model, the calculated results using the $k-\varepsilon$ model have fairly coincide with the water-model-experiment-results as shown for several turbulent-flow-case, within swirl-number of 1 , even with the considerably high tangential velocity of $2 \mathrm{~m} / \mathrm{s}$ in tube. ${ }^{3,4)}$ On the other case, the calculated results using the $k-\varepsilon$ model have not coincided with the experimental results, for the case (swirl number $\gg 1$ ). ${ }^{10}$ ) Namely, in the flow area within the swirl number less than 1 , calculation using the $k-\varepsilon$ model is considered to be effective. Accordingly, in this study $(\mathrm{Sw}=0.57)$, following equations were used because almost applied swirl numbers are within 1.

In general terms, the isothermal flow of an incompressible Newtonian fluid in a rectangular coordinate system is governed by well-known Navier-Stokes equations, which in our simulations take the following form:

$$
\begin{aligned}
& \frac{\partial \rho}{\partial t}+\frac{\partial u_{i}}{\partial x_{i}}=0 \\
& \frac{\partial u_{i}}{\partial t}+\frac{\partial}{\partial x_{j}}\left(u_{i} u_{j}\right)=-\frac{1}{\rho} \frac{\partial P}{\partial x_{i}}+v \frac{\partial^{2} u_{i}}{\partial x_{j} \partial x_{j}} S_{i} \ldots \ldots
\end{aligned}
$$

Here, indices $i, j$ represent components of velocity, $u_{i}$, i.e. $u, v, w$ and coordinate components, $x_{i},(X, Y, Z) ; v$, kinematic viscosity; $\rho$, density of the liquid; $P$, pressure and $S_{i}$ is the source term. Formula (1) is the equation of continuity, which states that within some domain, the amount of mass remains constant - mass is neither created nor destroyed. The second equation, the momentum equation, is simply the mass of an object multiplied by the velocity of the object, i.e. within some domain, the amount of momentum remains constant-momentum is neither created nor destroyed, but only changed as a result of the action of forces as described by Newton's law of motion.

The $k-\varepsilon$ turbulence two-equation model is the most widely used complete turbulence model, and it is employed in our calculations. The model incorporates one transport equation for $k$, one transport equation for $\varepsilon$, and the specification of the turbulent viscosity, ${ }^{11)}$ which is

$$
v_{\mathrm{T}}=C_{\mu} k^{2} / \varepsilon
$$

where $C_{\mu}=0.009$, is one of the five model constants.

The turbulence model is very well-known, therefore for details of the model, we ask the reader to refer to. ${ }^{1-11)}$ The values of the five empirical constants of the standard $k-\varepsilon$ turbulence model are given in Table $\mathbf{1}$.

In Table 2, water and steel parameters are summarized. All these parameters are set in the Fluent ${ }^{\mathbb{R}}$ solver.

Table 1. Turbulence model constants from the Fluent solver.

\begin{tabular}{lcccc}
\hline$C_{1}$ & $\boldsymbol{C}_{2}$ & $\boldsymbol{C}_{\boldsymbol{\mu}}$ & $\sigma_{k}$ & $\sigma_{\varepsilon}$ \\
1.44 & 1.92 & 0.09 & 1.0 & 1.3 \\
\hline Empirical constants: \\
$C_{1}$ - Coefficient of productive term in transport equation for $\varepsilon$. \\
$C_{2}$ - Coefficient of dissipative term in transport equation for $\varepsilon$. \\
$C_{\mu}$ - Coefficient in turbulent viscosity, i.e. $v_{T}$. \\
$\sigma_{K}$ - Turbulent Prandtl number. \\
$\sigma_{\varepsilon}$ - Prandtl number of $\varepsilon$.
\end{tabular}

\begin{tabular}{lcccc}
\hline & $\rho, \mathrm{kg} / \mathrm{m}^{3}$ & $\mu, \mathrm{kg} / \mathrm{m}-\mathrm{s}$ & $\kappa_{o}, \mathrm{~W} / \mathrm{m}-\mathrm{K}$ & $C_{P}, J / \mathrm{kg}-\mathrm{K}$ \\
Steel & 7200 & 0.006 & 46.4 & 628 \\
Water & 1000 & 0.001 & -- & -- \\
\hline
\end{tabular}

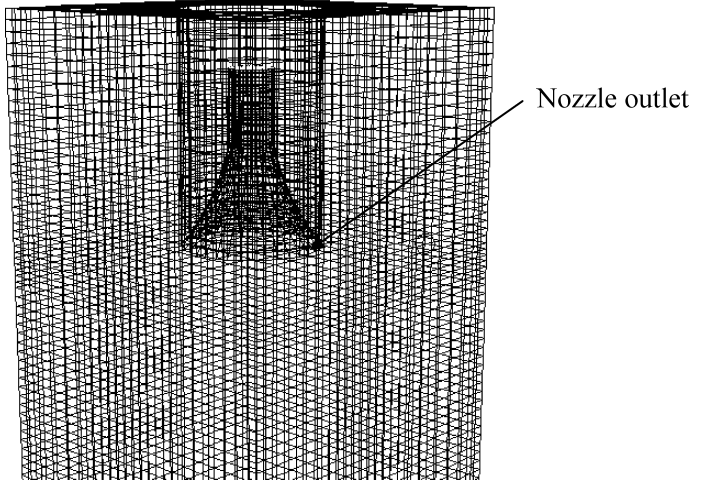

Fig. 3 Top part of computation domain.

\subsection{Boundary Conditions}

The swirl flow is obtained by a swirl blade, which is shown in Fig. 1. A radial profile of tangential velocity at a position $20 \mathrm{~mm}$ below the nozzle entrance is given, see Fig. 3. The mean tangential velocity $w$ is equal to $1.72 \mathrm{~m} / \mathrm{s}$. The mean tangential velocity can be expressed as follows:

$$
w=\frac{\omega \int_{0}^{R} 2 \pi r^{2} d r}{\pi r^{2}}
$$

where $R=9 \mathrm{~mm}$ (radius of the nozzle) and $\omega$ is angular velocity, which is calculated to be $286.7 \mathrm{rad} / \mathrm{s}$.

Other boundary conditions used in the mathematical model are:

- The mean axial velocity, $v$ is $2 \mathrm{~m} / \mathrm{s}$ and the mean angular velocity, $\omega$ is $286.7 \mathrm{rad} / \mathrm{s}$.

- Wall functions are used at solid walls. Slip wall boundary conditions are used at the free surface, which is assumed to be frictionless.

- A pressure outlet is used as a condition for the flow leaving the domain.

- For the molten steel calculations, the inlet temperature is $1773 \mathrm{~K}$ and the wall temperature is $1748 \mathrm{~K}$, see Fig. 1, and Table 2.

\subsection{Method of Solution}

Mesh is generated on Gambit ${ }^{\mathbb{R}}$ which is a pre-processor of Fluent ${ }^{\circledR}$ solver. A structured grid consisting of 119640 nodes and having 109213 hexahedral cells was used in the calculations. A dense mesh, with good near-wall treatment, was employed for the computational domain in order to obtain accurate results, as shown in Fig. 3. The solutions of the governing equations including source terms and boundary conditions were obtained using the commercial software package Fluent ${ }^{\circledR} .{ }^{12)}$ Second order upwind discretization schemes were used for modelling for turbulence and PRESTO and QUICK for pressure and momentum parameters. ${ }^{10)}$ Additionally, a turbulence intensity of $6 \%$ was used to account for effects of turbulence, both in water-model and molten steel calculations. Turbulence intensity is deter- 
mined by the Reynolds number, which itself characterizes the relative importance of inertial and viscous forces in a flow, and the value of $6 \%$ is approximate, and determined by calculations. In our studies, the Reynolds number was experimentally measured and found to be 38000 ; thus moderate turbulent intensity was necessary as an input into the solver.

Calculations were made with a time-steady scheme taking into consideration low residual criterion $\left(10^{-5}\right)$ for improved accuracy. As an example, calculations for the earlier mentioned mesh took approximately $5 \mathrm{~h} 15 \mathrm{~min}$ using an Intel $3600 \mathrm{MHz}$ processor.

\section{Results}

In the systematic approach used during this work, watermodel tests were carried out first. After developing a verified model, a CC billet mould having $0-160^{\circ}$ divergent angle of the immersion nozzle outlet was studied (see Fig. 2 for a schematic representation of $\Phi$ divergent angle in the immersion nozzle).

First, flow patterns were studied inside the mould and near the meniscus. Thereafter, heat transfer was included and investigations for superheat dissipation were carried out. Details of the study are discussed in the following paragraphs.

\subsection{Water-model Experiment Verification}

The mean axial velocity through the tube was measured by an electromagnetic velocimeter, and was found to be $2 \mathrm{~m} / \mathrm{s}$. Tangential velocity was also measured. Fig. 4 shows the radial profile of tangential velocity. Its mean value was calculated to be $1.72 \mathrm{~m} / \mathrm{s}$. The Reynolds number was measured, and found to be 38000 , which is a moderately turbulent flow.

Figure 5 shows flow pattern and velocity contours along at the vertical plane through the mould axis. It was observed that the bulk of flow leaving the nozzle outlet splits into two circulation parts, upper and lower. The upper circulating bulk then flows upwards close to the mould corner walls, up to the region near the meniscus. Thus, in total there are four upward circulating flows. The lower circulating bulk also flows upwards, with some fluid moving downwards. In general, the flow pattern is such that it passes down along the walls and up in the middle, which is the reason that the velocity gradients inside the mould are not so high.

Experimentally measured and calculated horizontal pro-

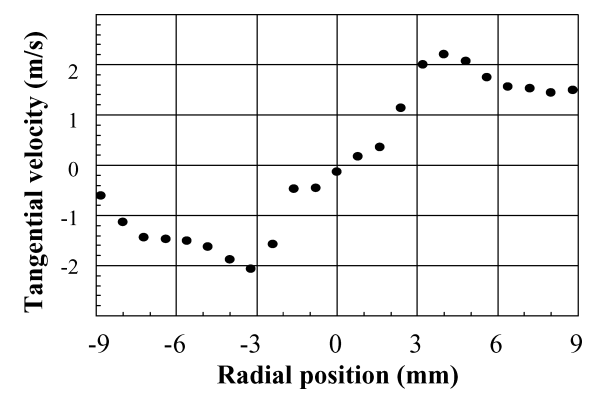

Fig. 4. Radial profile of tangential velocity measured $20 \mathrm{~mm}$ below entrance of nozzle. files of the axial velocity component at several axial positions below the nozzle outlet on the plane through the mould axis are shown in Fig. 6. The agreement between measurements and calculations are in general good. However, at the positions near the nozzle exit some small divergence can be observed in the region of $-30<X<30 \mathrm{~mm}$.

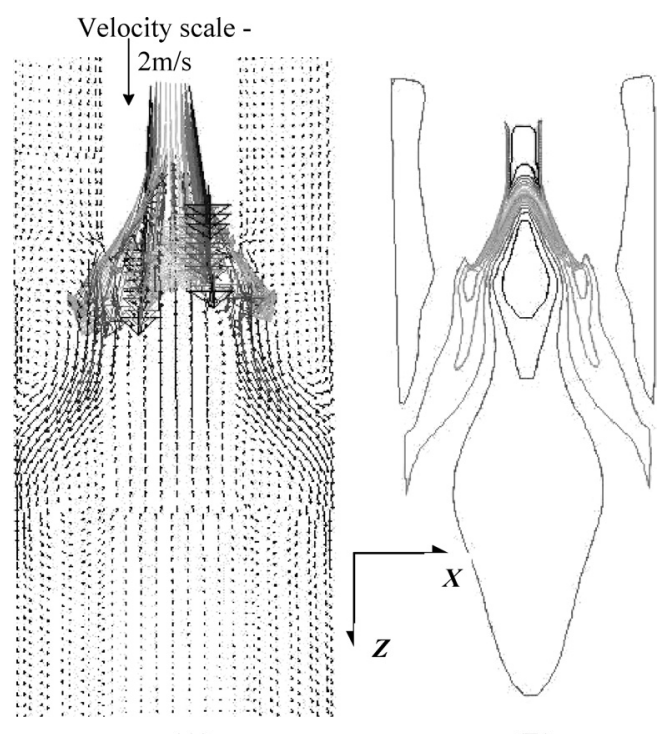

(A)

(B)

Fig. 5. Calculated flow pattern (A) and velocity contour plot (B) for square billet mould with $90^{\circ}$ nozzle outlet along the vertical cross-sectional plane.
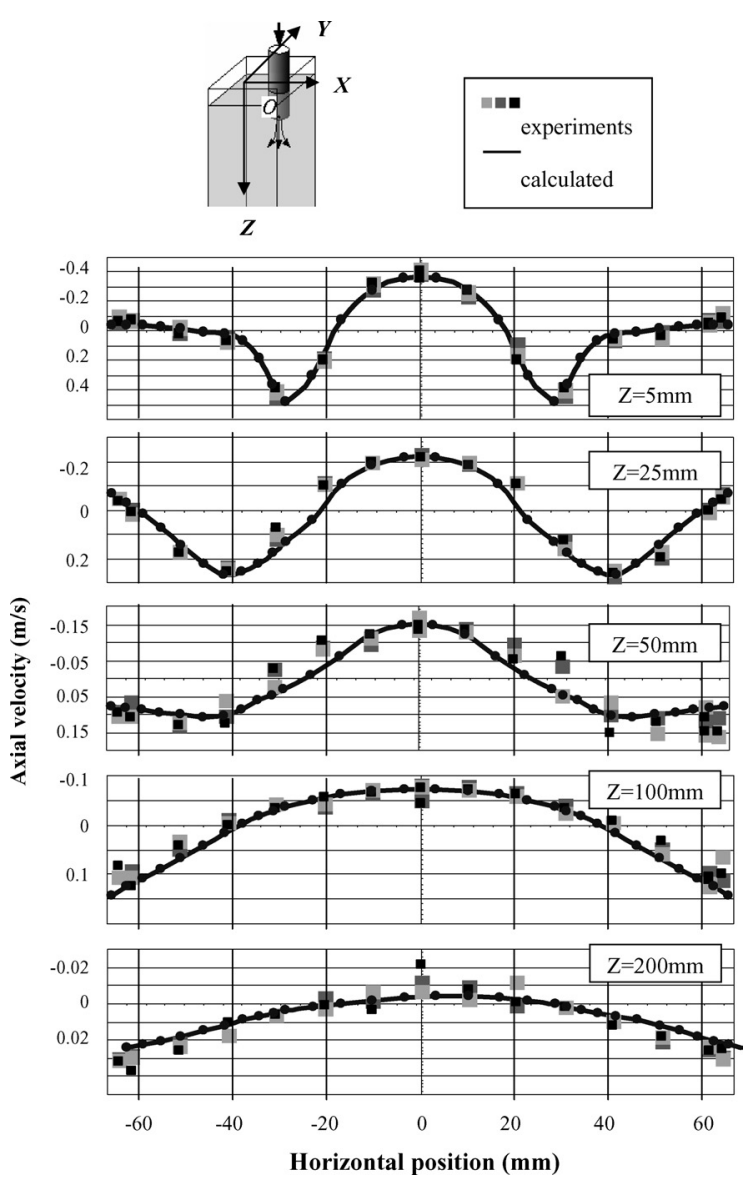

Fig. 6. Calculated vs. experimentally measured axial component of velocity profile along the $X Z$ plane flow with inlet axial of $2 \mathrm{~m} / \mathrm{s}$, and mean swirl velocity of $1.72 \mathrm{~m} / \mathrm{s}$. 


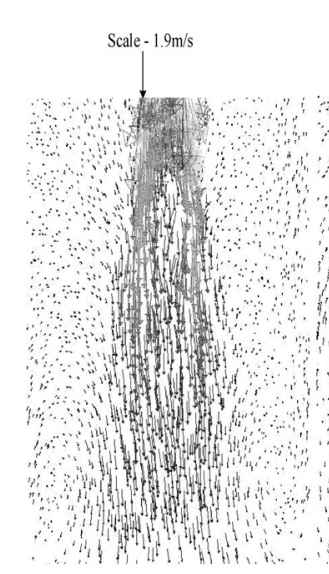

(A)

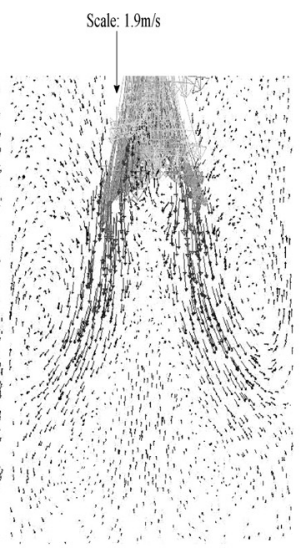

(B)

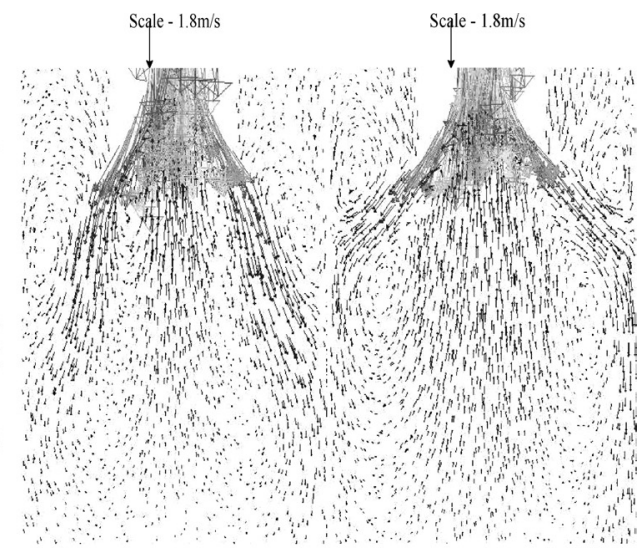

(C)

(D)

Fig. 7. Flow patterns for (A) $20^{\circ}$ (B) $40^{\circ}$ (C) $80^{\circ}$ and (D) $100^{\circ}$ divergent angle nozzles with $2 \mathrm{~m} / \mathrm{s}$, and $1.72 \mathrm{~m} / \mathrm{s}$ (mean axial and tangential velocities, respectively) at the region below nozzle exit.

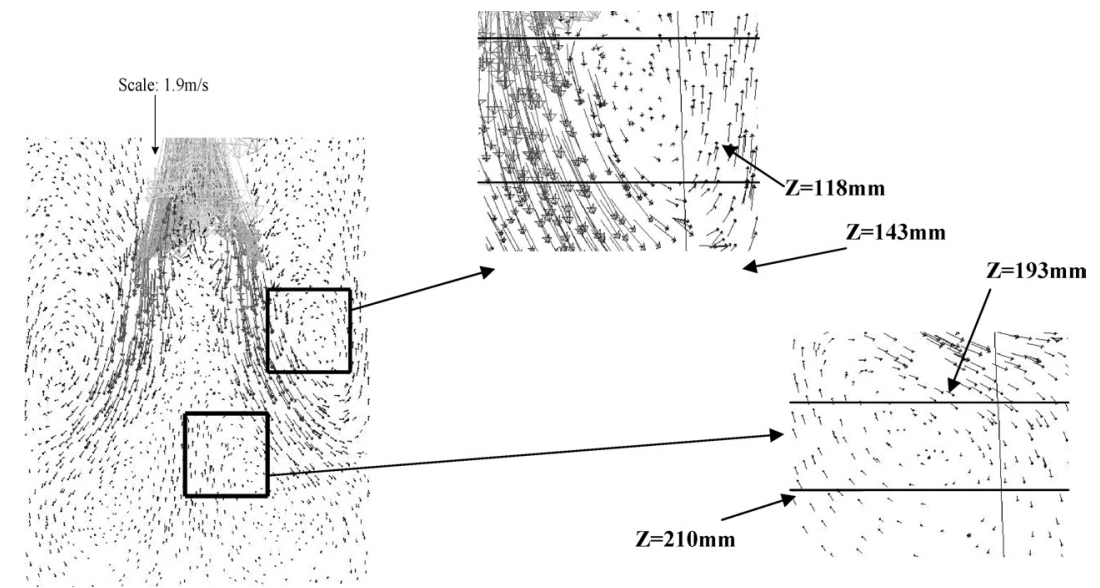

Fig. 8. Close view to upper and lower circulation regions (Fig. 7) of billet mould with $40^{\circ}$ divergent angle degree (Z, distance from the meniscus).

This is most likely to be the result of uncertainties about whether or not turbulence model is accurate enough in this highly turbulent area. But, as we look further down, at $100 \mathrm{~mm}$ below the nozzle exit, calculations reproduce the experimental results. Further investigation focusing on this behaviour seems to be necessary.

\subsection{Flow Pattern Inside the Mould and Near Meniscus}

Square billet continuous caster moulds, having $0^{\circ}-160^{\circ}$ divergent angles in the immersion nozzle have been extensively studied. Clearly, for the $0^{\circ}$ divergent angle, i.e. the straight immersion nozzle, the flow must pass straight down and then upwards close to the mould walls. As the divergent angle increases the flow bulk leaving the nozzle exit starts turning to the sides, and when it reaches the walls it splits into two circulating regions. These regions can be described as an upper circulation, where the fluid move upwards close to the mould walls and downwards near the nozzle walls, and a lower circulation, where the bulk passes downwards near the mould walls and upwards near the centre of the mould. Thus, velocity gradients within the mould decrease as the divergent angle increases.

In Fig. 7 flow patterns of $20-100^{\circ}$ nozzle outlet divergent angles in the mould at plane through mould axis are presented. In Fig. 8 close views of these regions are shown for one case. For the case representing a square billet with a $20^{\circ}$ divergent angle in the immersion nozzle, lower circulation is located at a distance from the meniscus, the centre of circulation being located approximately $200 \mathrm{~mm}$ below the meniscus. For the case of the $100^{\circ}$ nozzle, a large shift of the lower circulation centre is observed compared to that of the $80^{\circ}$ nozzle. Moreover, for the $100^{\circ}$ nozzle caster billet, the flow pattern is very divergent, with fluid splitting into almost two equal fluid flows moving upwards and downwards. With the $120^{\circ}$ nozzle, the centre of the upper recirculation is seen to be located close to the nozzle exit $(94 \mathrm{~mm})$, and for even larger divergent degree nozzles a further shift was upwards found. Fig. 9 shows the effect of divergent angle on the centre positions of circulating flow.

Figure 10 shows numerically determined velocity distribution on the horizontal planes, positioned at 100 and $200 \mathrm{~mm}$ below the nozzle exit. It is clear that circulation, covering the whole plane, has not formed even at a distance of $200 \mathrm{~mm}$ below the nozzle exit for the $20^{\circ}$ nozzle, where the flow pattern is rather twisting. For the $100^{\circ}$ nozzle a rather small circulation can be observed at $200 \mathrm{~mm}$ below the nozzle exit. The circulation became uniform with increasing divergent angle. A calm impinging flow, near the corner of the mould wall having a uniform velocity distribution, is observed. This flow results in a relatively uniform 
temperature distribution, which is illustrated on Fig. 11.

Figure 12 shows the numerically calculated axial velocity component at several axial positions on the plane through mould axis $(Y=0)$. For cases of $0^{\circ}$ and $20^{\circ}$ divergent nozzles, it is clear that the flow is strongest between $-20<$ $X<20 \mathrm{~mm}$, in the region below the nozzle exit. It should also be noted that for these two cases, even at the distance of $200 \mathrm{~mm}$ below the nozzle exit, the bulk of the fluid is mainly passing downwards; thus axial velocity is mainly positive. Starting from the $100^{\circ}$ nozzle billet we can observe rather uniform velocity distribution at the distance of $25 \mathrm{~mm}$ below nozzle exit. This uniform velocity pattern is also observed for the case of the $80^{\circ}$ nozzle billet at a distance of $100 \mathrm{~mm}$. For all nozzles, the flow is strongest at the point closest to the nozzle walls, whereas at mould centre $(X=0)$ it is weak; this is a direct result of swirl motion, in which fluid leaving the nozzle exit shows a greater axial velocity component when close to the nozzle walls.

Figure 13 shows the flow pattern for three sample cases, $60^{\circ}, 100^{\circ}$ and $160^{\circ}$ divergent angle nozzle billet moulds. A strong upward flow, which is observed for the billets with

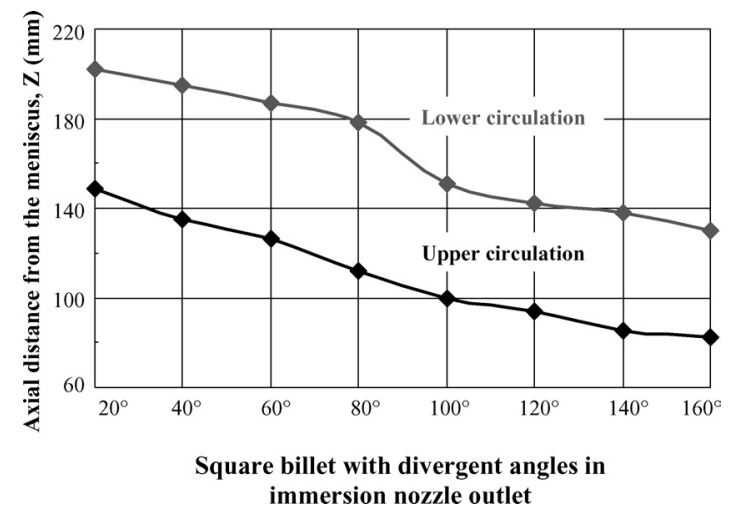

Fig. 9. Centre positions of upper and lower circulations for various divergent angle nozzles. $100^{\circ}$ divergent nozzle and greater, leads to an inflow into the meniscus from the parts of the mould-corner, and an outflow around the nozzle outer region, as shown on Figs. 13(B), 13(C). Figure 14 shows horizontal velocity profile. This calculation is made at an axial distance of $3 \mathrm{~mm}$ below the meniscus. A slight increase in horizontal velocity is observed for the $160^{\circ}$ nozzle, compared to the other billets. In Fig. 14 we can see that an increasing divergent angle of the immersion nozzle also causes the horizontal velocity component to increase, most accentuated in the region $35<$ $X<55 \mathrm{~mm}$. For the $20^{\circ}$ nozzle, the horizontal velocity profile appears to be rather uniformly distributed, whereas for the larger divergent angle nozzle the highest horizontal velocities are found in the middle range.

\subsection{Temperature Distribution Inside the Mould and Near the Meniscus}

The calculated horizontal profile of the temperature is

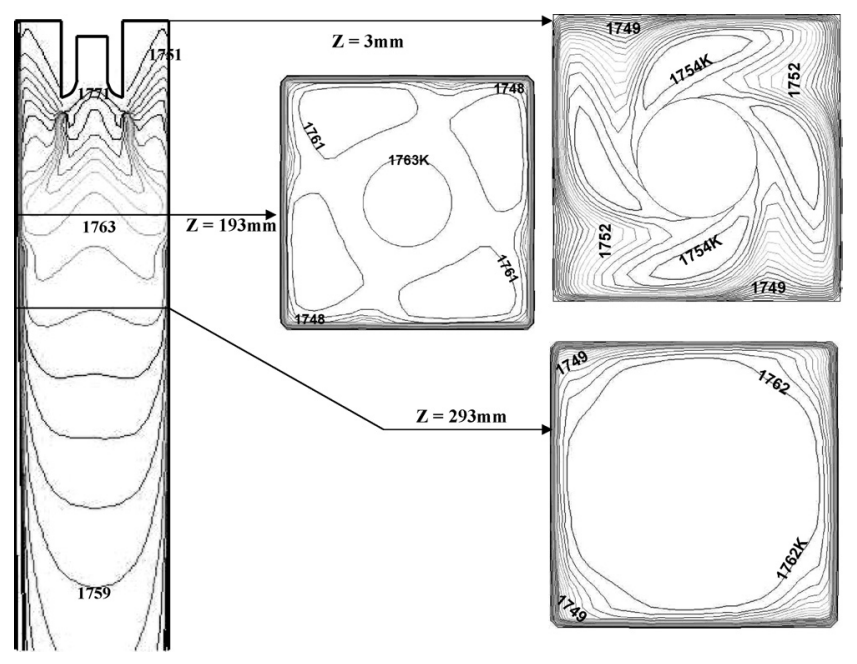

Fig. 11. Temperature contour plots through mould axis and horizontal planes for $100^{\circ}$-divergent angle nozzle.

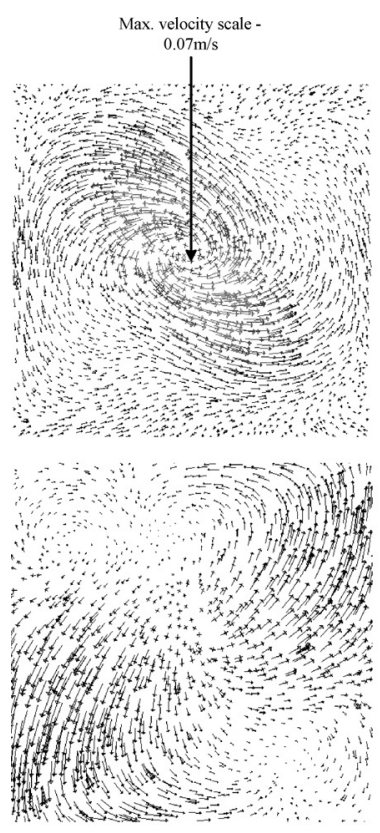

(A)
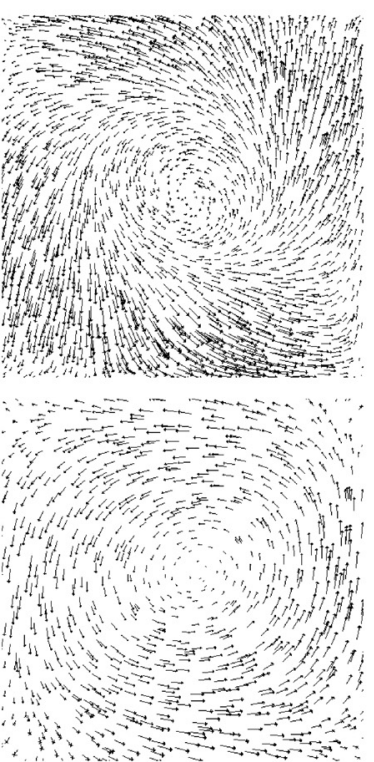

(B)

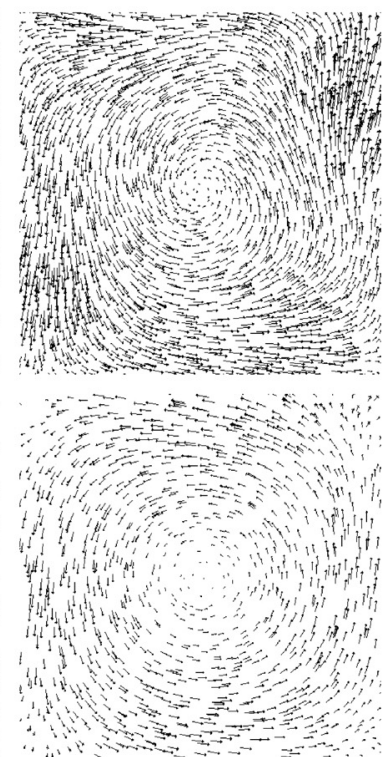

(C)

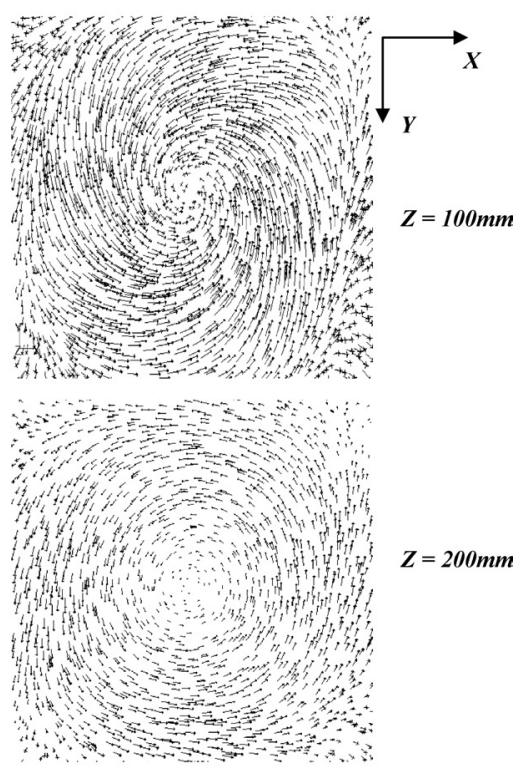

(D)

Fig. 10. Flow patterns for (A) $20^{\circ}$ (B) $40^{\circ}$ (C) $80^{\circ}$ and (D) $100^{\circ}$-divergent nozzles with $2 \mathrm{~m} / \mathrm{s}$, and $1.72 \mathrm{~m} / \mathrm{s}$ (mean axial and tangential velocities, respectively) at horizontal $X Y$ plane (distance from meniscus). 


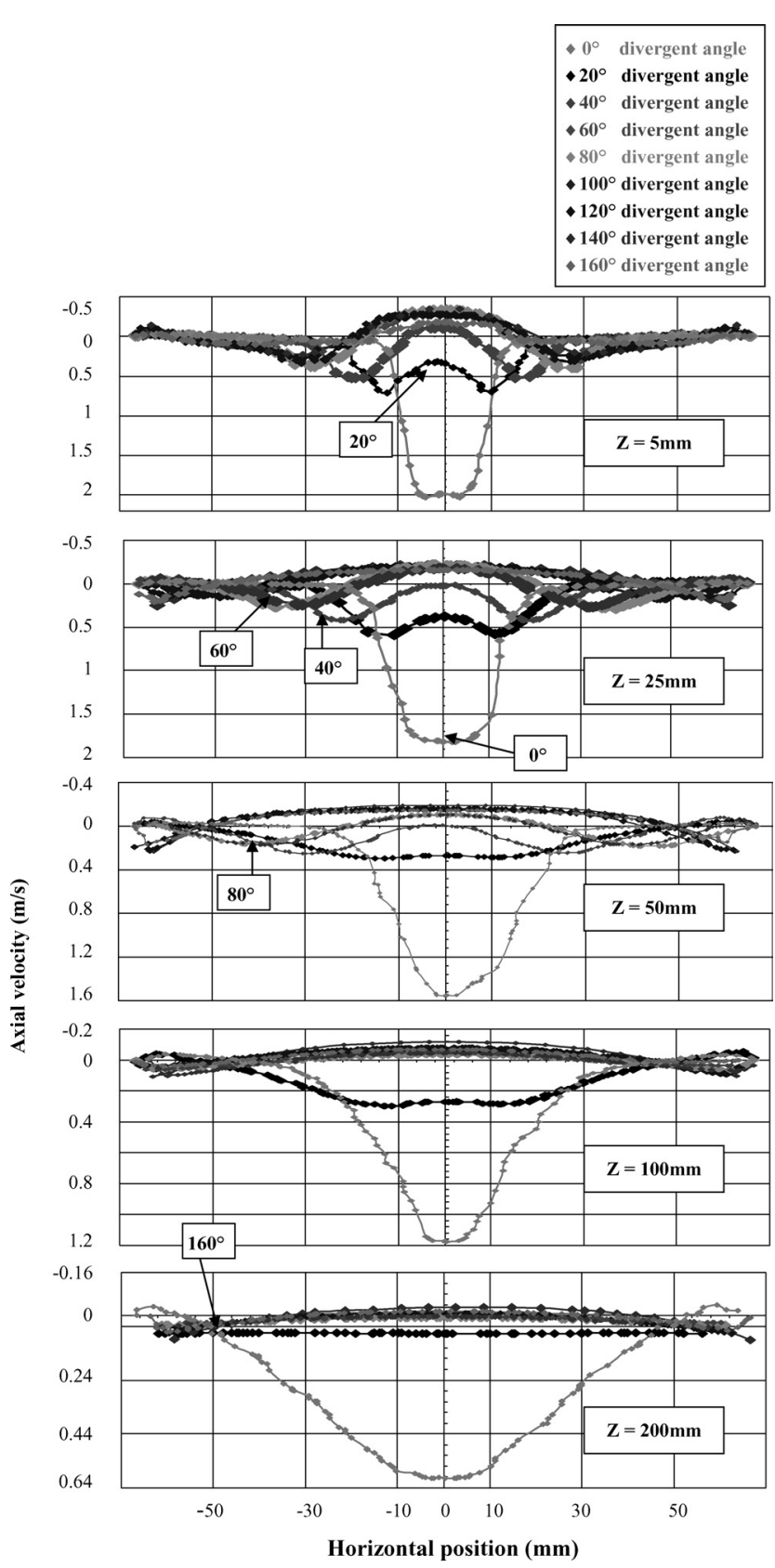

Fig. 12. Calculated axial velocity component at plane through the nozzle exit $(Y=0)$ with mean axial and tangential velocities of $2 \mathrm{~m} / \mathrm{s}$, and $1.72 \mathrm{~m} / \mathrm{s}$. shown on Fig. 15. We can see that the temperature is highest in the first half of the region between the nozzle wall and the mould wall, with a high magnitude close to the nozzle outlet wall in some cases with a rising, and in other cases constant, magnitude. For the $10^{\circ}$ and $20^{\circ}$ divergent nozzle billets, the temperature fields are rather uniformly distributed, and almost no temperature increase is observed. An interesting phenomenon is that, in the cases of the billet moulds with $80^{\circ}$ and $100^{\circ}$ divergent nozzles, the temperature magnitude rises sharply, compared with the other cases investigated. This phenomena might be due to the flow pattern, which was discussed earlier; in the case of the square billet with the $80^{\circ}$ divergent angle nozzle, the nozzle centre-point of the upper circulation region is located $112 \mathrm{~mm}$ below the nozzle exit, whereas in the $100^{\circ}$ divergent angle case, this point is $100 \mathrm{~mm}$ from the nozzle exit (Fig. 9), increasing the fluid bulk passing upwards to the meniscus and thus noticeably increasing the temperature close to the

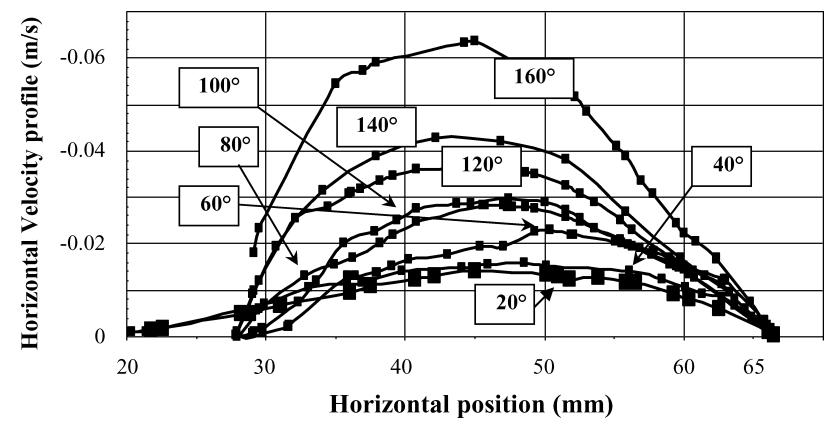

Fig. 14. Calculated horizontal velocity profile on line near meniscus $(Y=0)$.

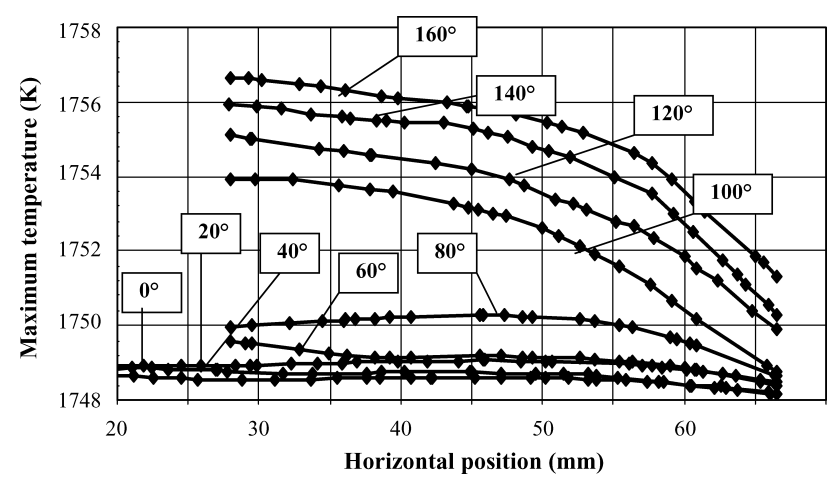

Fig. 15. Calculated profile of horizontal temperature near meniscus $(Y=0)$.

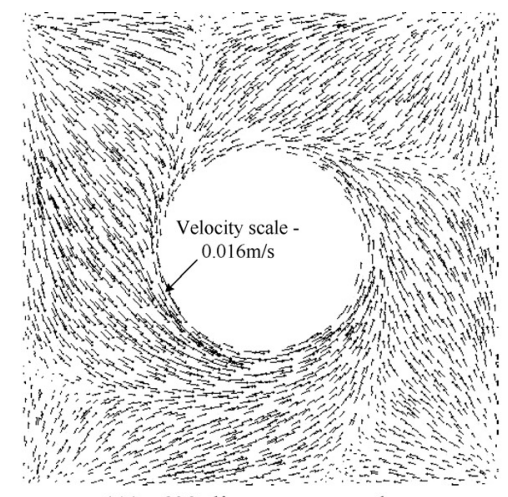

(A) $60^{\circ}$ divergent nozzle

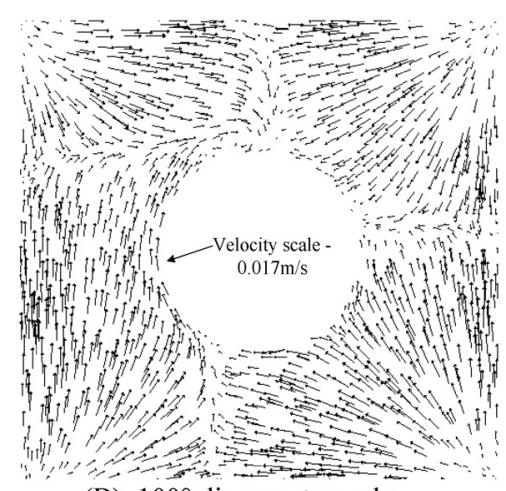

(B) $100^{\circ}$ divergent nozzle

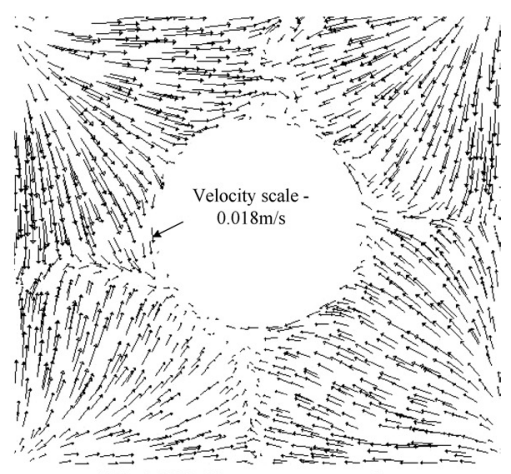

(C) $160^{\circ}$ divergent nozzle

Fig. 13. Flow patterns for (A) $60^{\circ}$ (B) $100^{\circ}$ and (C) $160^{\circ}$ divergent angle nozzles on horizontal plane near the meniscus. 
meniscus. For other cases the temperature rise was not noticeable.

Figure 11 shows contour plots of the temperature field for the $100^{\circ}$ nozzle outlet on planes through the mould axis, and horizontal planes through meniscus, 100 and $200 \mathrm{~mm}$ below the nozzle exit. Calm impinging flow near the corner of the mould wall and uniform velocity distribution all around the plane was observed $200 \mathrm{~mm}$ below nozzle exit (Fig. 10(D)), resulting in the uniformly distributed temperature field shown in Fig. 11. Also, a uniform distribution is seen close to the meniscus. As expected, an axi-symmetric temperature field is observed throughout the mould.

\section{Conclusions}

The effect of changing the divergent angle of an immersion nozzle outlet on flow pattern and temperature distribution was investigated. Studies were carried out employing swirl flow on 3D square billet continuous caster moulds using experimental measurement and mathematical modelling.

The following conclusions are drawn:

(1) For billets with divergent angle degrees of $100^{\circ}$ and greater in the immersion nozzle, the centre point of the upper circulation is observed near or above the nozzle exit, which results in increased temperature near the meniscus.

(2) A noticeable increase of the temperature field near the meniscus was observed for the square billet with a $100^{\circ}$ divergent angle in the immersion nozzle compared to that with a $80^{\circ}$ divergent angle.

(3) An upward flow from the vicinity of the nozzle outlet to the meniscus can be observed near the corner of the upper part of the mould, which leads to active heat and mass transfer into the meniscus.

(4) A uniform velocity and heat distribution can be observed within a distance of $200 \mathrm{~mm}$ below the nozzle exit for nozzle outlets with a $100^{\circ}$ divergent angle and greater.

\section{Acknowledgment}

The authors wish to thank Kami Research Foundation for their financial support of this study.

\section{REFERENCES}

1) S. Yokoya, P. G. Jönsson, K. Sasaki, K. Tada, S. Tagaki and M. Iguchi: Scand. J. Metall., 33 (2004), 22.

2) S. Yokoya, S. Tagaki, M. Iguchi, Y. Asako, R. Westoff and S. Hara: ISIJ Int., 38 (1998), 827.

3) S. Yokoya, Y. Asako, S. Hara and J. Szekely: ISIJ Int., 34 (1994), 883.

4) S. Yokoya, R. Westoff, Y. Asako, S. Hara and J. Szekely: ISIJ Int., 34 (1994), 889.

5) S. Yokoya, S. Takagi, K. Tada, M. Iguchi, K. Marukawa and S. Hara: ISIJ Int., 41 (2001), 1201.

6) S. Yokoya, S. Takagi, S. Ootani, M. Iguchi, K. Marukawa and S. Hara: ISIJ Int., 41 (2001), 1208.

7) S. Yokoya, S. Takagi, M. Kaneko, M. Iguchi, K. Marukawa and S. Hara: ISIJ Int., 41 (2001), 1215.

8) S. Yokoya, S. Takagi, M. Iguchi, K. Marukawa and S. Hara: ISIJ Int., 41 (2001), S47.

9) B. G. Thomas: Proc. 59th Electric Furnace Conf., Iron and Steel Society, Warrendale, PA, (2001), 3 .

10) S. Yokoya, S. Takagi, K. Marukawa M. Iguchi, and S. Hara: CAMPISIJ, 13 (2000), 81.

11) B. Pope: Turbulence Flows, Cornell University, Cambridge University Press, (2000).

12) Fluent Documentation, Fluent Inc., Lebanon NH, USA, (2005). 